\title{
INTERNATIONAL RED CROSS MUSEUM
}

The International Reviere has published several articles about the Museum and the various events since it was installed at Castiglione delle Stiviere, in the beautiful Longhi palace. As one enters, one can admire the fine sequence of halls with their decorated ceilings, on three floors. The entrance lobby leads into the garden where, under the vaulting, sketches and samples of medical material used by the Italian Red Cross during the last century and until recently can be seen.

This year, Mr. E. Mutti, director of the museum, is organizing an exhibition with co-operation from the ICRC. It is to be inaugurated in the presence of the presidents of several regional sections of the Italian Red Cross, representatives of provincial and local authorities and of the international institutions of the Red Cross. It will be open to the public until 10 October 1974. Having as its theme From Solferino to the Present, it will include a large number of illustrations and reproductions of documents supplied by the ICRC, consisting mainily of pictures of the battle of Solferino, and dealing with the care which the women of Castiglione gave the wounded who had been brought there, and with the generous response of all the inhabitants of that town, the signing of the first Geneva Convention, the text of that Convention, and other landmarks in the history of the Red Cross.

We hope the exhibition will be very successful and that many of those who spend that time of the year in northern Italy will visit it. In the International Museum they will see an illustration of the growth of the Red Cross movement and the impetus that will carry it through the world. 